ARTICLE

\title{
Pseudocapacitance of MXene nanosheets for high-power sodium-ion hybrid capacitors
}

\author{
Xianfen Wang ${ }^{1}$, Satoshi Kajiyama ${ }^{1}$, Hiroki linuma', Eiji Hosono², Shinji Oro³ ${ }^{3}$ Isamu Moriguchi ${ }^{3}$, Masashi Okubo ${ }^{1,4}$ \\ \& Atsuo Yamada ${ }^{1,4}$
}

High-power $\mathrm{Na}$-ion batteries have tremendous potential in various large-scale applications. However, conventional charge storage through ion intercalation or double-layer formation cannot satisfy the requirements of such applications owing to the slow kinetics of ion intercalation and the small capacitance of the double layer. The present work demonstrates that the pseudocapacitance of the nanosheet compound MXene $\mathrm{Ti}_{2} \mathrm{C}$ achieves a higher specific capacity relative to double-layer capacitor electrodes and a higher rate capability relative to ion intercalation electrodes. By utilizing the pseudocapacitance as a negative electrode, the prototype Na-ion full cell consisting of an alluaudite $\mathrm{Na}_{2} \mathrm{Fe}_{2}\left(\mathrm{SO}_{4}\right)_{3}$ positive electrode and an $\mathrm{MXene} \mathrm{Ti}_{2} \mathrm{C}$ negative electrode operates at a relatively high voltage of $2.4 \mathrm{~V}$ and delivers 90 and $40 \mathrm{mAhg}^{-1}$ at 1.0 and $5.0 \mathrm{Ag}^{-1}$ (based on the weight of the negative electrode), respectively, which are not attainable by conventional electrochemical energy storage systems.

\footnotetext{
${ }^{1}$ Department of Chemical System Engineering, School of Engineering, The University of Tokyo, Hongo 7-3-1, Bunkyo-ku, Tokyo 113-8656, Japan.

${ }^{2}$ National Institute of Advanced Industrial Science and Technology, Umezono 1-1-1, Tsukuba 305-8568, Japan. ${ }^{3}$ Graduate School of Engineering, Nagasaki University, Bunkyo-machi 1-14, Nagasaki 852-8521, Japan. ${ }^{4}$ Elements Strategy Initiative for Catalysts and Batteries (ESICB), Kyoto University, Nishikyo-ku, Kyoto 615-8510, Japan. Correspondence and requests for materials should be addressed to A.Y. (email: yamada@chemsys.t.u-tokyo.ac.jp).
} 
E lectrochemical energy storage capable of more energy at high charge-discharge rates is receiving considerable attention because of the strong industrial demands for their widespread use in the smart grid. High-energy Li-ion batteries consisting of $\mathrm{Li}^{+}$(de)intercalation electrodes currently power most portable electronics, but the power density is not satisfactory for high-power applications ${ }^{1,2}$. High-power electrochemical capacitors make up many markets ranging from electronics to transportation and stationary applications, but the low energy density is a serious disadvantage ${ }^{3,4}$. This tradeoff between the power and energy densities of electrochemical energy storage has been well recognized, which intrinsically originates from the charge storage mechanism of the electrodes: ion (de)intercalation in batteries and double-layer formation in electrochemical capacitors. In general, ion (de)intercalation stores charge more slowly than a double layer, whereas a double layer stores less charge than ion (de)intercalation ${ }^{3}$. Thus, the pseudocapacitance (or redox capacitance) has become an increasingly important mechanism for charge storage ${ }^{5-10}$. Pseudocapacitance occurs through (i) monolayer ion adsorption on the electrode surface with charge transfer, (ii) redox at the electrode surface $\left(\mathrm{RuO}_{2} \cdot x \mathrm{H}_{2} \mathrm{O}\right.$, ref. 5) or (iii) ultrafast ion intercalation into the bulk $\left(T-\mathrm{Nb}_{2} \mathrm{O}_{5}\right.$, ref. 6), whereby charge storage is partially liberated from the trade-off.

At present, urgent concerns over lithium resources have focused recent attention on $\mathrm{Na}$-ion batteries owing to the abundance and low cost of sodium. The present set of negativeelectrode materials for $\mathrm{Na}$-ion batteries mainly consists of $\mathrm{Na}$-ion intercalation, alloying or conversion materials such as hard carbon, expanded graphite, $\mathrm{TiO}_{2}, \mathrm{Na}_{2} \mathrm{Ti}_{3} \mathrm{O}_{7}$, phosphorus, $\mathrm{Sb}_{2} \mathrm{~S}_{3}$, $\mathrm{Sn}_{4+x} \mathrm{P}_{3}, \quad \mathrm{SnS}_{2}$ and $\mathrm{P} 2-\mathrm{Na}_{0.66}\left[\mathrm{Li}_{0.22} \mathrm{Ti}_{0.78}\right] \mathrm{O}_{2}$ (refs 11-19). However, their energy and power densities severely suffer from the trade-off, and the large volume change accompanied by the reaction with the large $\mathrm{Na}$ ion generally results in poor cycle stability, both of which have spurred us to develop new negative electrodes based on pseudocapacitive charge storage for advanced Na-ion systems.

We have targeted MXenes as pseudocapacitor electrodes in this study. MXenes have been developed as a novel family of nanosheet compounds by Gogotsi, Barsoum and colleagues ${ }^{20-25}$ MXenes are chemically derived from layered $M_{n+1} A X_{n}$ or MAX phases, where $M$ is an early transition metal, $A$ is an A-group element and $X$ is $\mathrm{C}$ and/or $\mathrm{N}^{26}$. For example, a hydrofluoric-acid treatment of $\mathrm{Ti}_{3} \mathrm{AlC}_{2}$ selectively extracts the aluminum layer, resulting in an exfoliated nanosheet compound, the MXene $\mathrm{Ti}_{3} \mathrm{C}_{2}$ $\left(\mathrm{Ti}_{3} \mathrm{C}_{2} \mathrm{~T}_{x}\right.$ where $\mathrm{T}_{x}$ denotes surface function groups), which has a surface terminated with $\mathrm{OH}, \mathrm{F}$ and $\mathrm{O}$. Importantly, the MXene has both a high electrical conductivity and large surface area; therefore, its application to pseudocapacitor electrodes holds great promise. Indeed, the pseudocapacitance of $\mathrm{Ti}_{3} \mathrm{C}_{2} \mathrm{~T}_{x}, \mathrm{Ti}_{2} \mathrm{CT}_{x}$, $\mathrm{V}_{2} \mathrm{CT}_{x}$ and $\mathrm{Nb}_{2} \mathrm{CT}_{x}$ in nonaqueous Li-ion electrolytes delivers a specific capacity $>100 \mathrm{mAhg}^{-1}$ below $2 \mathrm{~V}$ versus $\mathrm{Li} / \mathrm{Li}^{+}$ (refs 22,27-32).

Here, we report on $\mathrm{Ti}_{2} \mathrm{CT}_{x}$ as a negative electrode material for Na-ion hybrid capacitors. The pseudocapacitance of $\mathrm{Ti}_{2} \mathrm{CT}_{x}$ allows $\mathrm{Na}$-ion hybrid capacitors to be liberated from the trade-off between high energy and high power.

\section{Results}

Electrochemical properties of $\mathrm{Ti}_{2} \mathrm{CT}_{\boldsymbol{x}}$. $\mathrm{Ti}_{2} \mathrm{CT}_{x}$ was synthesized by treating the MAX phase $\mathrm{Ti}_{2} \mathrm{AlC}$ with a $10 \% \mathrm{HF}$ aqueous solution. Powder X-ray diffraction (XRD) shows the expansion of the interlayer distance by the hydrofluoric acid (HF) treatment, suggesting successful removal of the $\mathrm{Al}$ layers by the HF treatment (Supplementary Fig. 1). The significant decrease in the amount of $\mathrm{Al}$ according to energy dispersive X-ray spectroscopy (EDX) supports the selective extraction of $\mathrm{Al}$. A delamination process such as sonication was not conducted ${ }^{22}$; therefore, $\mathrm{Ti}_{2} \mathrm{CT}_{x}$ in this work is a multilayered MXene, as imaged by scanning electron microscopy (Supplementary Fig. 2).

The $\mathrm{Ti}_{2} \mathrm{CT}_{x}$ electrode in a nonaqueous $\mathrm{Na}^{+}$electrolyte behaves differently than in an aqueous $\mathrm{Na}^{+}$electrolyte or a nonaqueous $\mathrm{Li}^{+}$electrolyte. Figure $1 \mathrm{a}$ shows the cyclic voltammetry (CV) and corresponding ex situ XRD patterns of the MXene $\mathrm{Ti}_{2} \mathrm{C}$ in a $1 \mathrm{M} \mathrm{NaPF}_{6}$ /ethylene carbonate (EC) diethyl carbonate (DEC) electrolyte. Lukatskaya et al. ${ }^{23}$ reported that $\mathrm{Ti}_{3} \mathrm{C}_{2} \mathrm{~T}_{x}$ placed in various aqueous salt $(\mathrm{NaOH}, \mathrm{KOH}, \mathrm{LiOH}$ and so on) solutions exhibits a downshift in the (002) diffraction peak in the XRD pattern, corresponding to spontaneous cation intercalation. In contrast, $\mathrm{Ti}_{2} \mathrm{CT}_{x}$ immersed in a nonaqueous $1 \mathrm{M}$ $\mathrm{NaPF}_{6} / \mathrm{EC}-\mathrm{DEC}$ electrolyte exhibits no downshift in the (002) diffraction peak by immersion into the electrolyte alone, which indicates that $\mathrm{Na}^{+}$intercalation does not occur spontaneously. The first cathodic scan exhibits an irreversible current below $1.0 \mathrm{~V}$ versus $\mathrm{Na} / \mathrm{Na}^{+}$and an associated downshift in the (002) diffraction peak. As EDX confirms an increase in the $\mathrm{Na}$ content in $\mathrm{Ti}_{2} \mathrm{CT}_{x}$ (Supplementary Table S1), $\mathrm{Na}^{+}$is definitely intercalated/adsorbed into/onto the MXene sheets electrochemically. On the basis of the shift in the (002) diffraction peak, the expansion of the interlayer distance is estimated as $2.5 \AA$. The expansion is also confirmed by transmission electron microscopy images (Fig. 1b,c). Because the expansion is consistent with the size of bare $\mathrm{Na}^{+}, \mathrm{Na}^{+}$ intercalation occurs after desolvation at the electrode/electrolyte interface during the initial reduction process (Fig. 2, activation).

After initial $\mathrm{Na}^{+}$intercalation, $\mathrm{Ti}_{2} \mathrm{CT}_{x}$ exhibits pseudocapacitor behaviour. The subsequent $\mathrm{CV}$ cycles after the first cycle exhibit the stable rectangular-shaped $\mathrm{CV}$ below $\sim 2.0 \mathrm{~V}$,
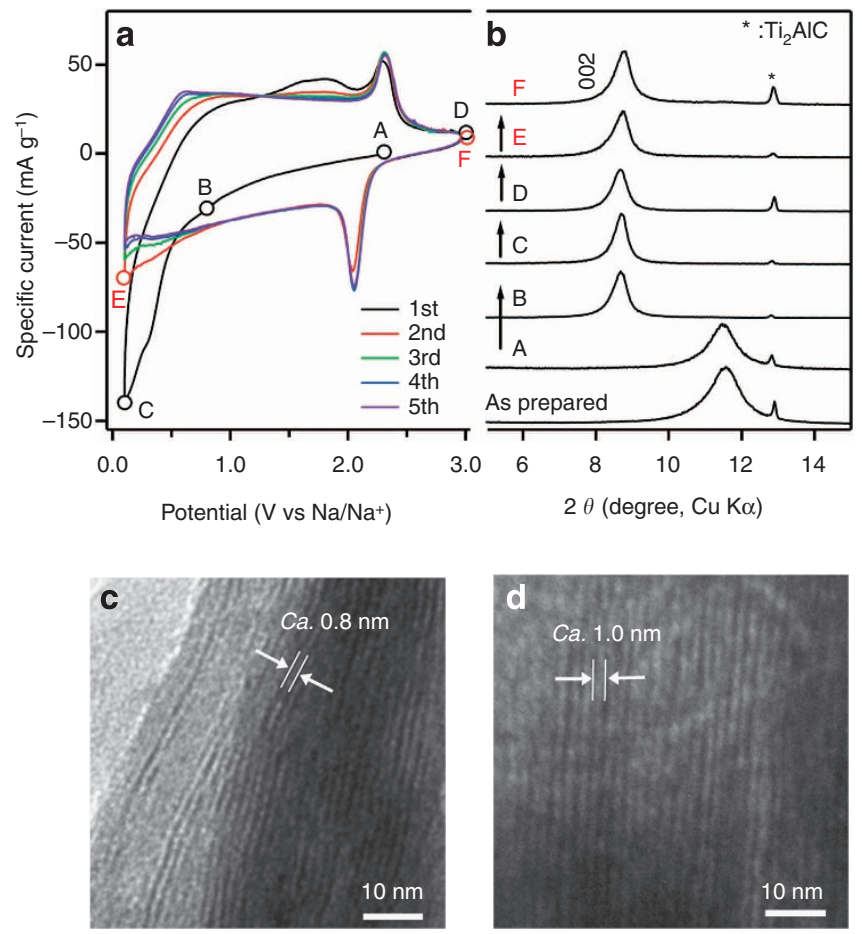

Figure 1 | Electrochemical properties and associated structural changes of the $\mathbf{T i}_{\mathbf{2}} \mathbf{C T}_{\boldsymbol{x}}$ (a) $\mathrm{CV}$ for $\mathrm{Ti}_{2} \mathrm{CT}_{x}$ in a $1 \mathrm{M} \mathrm{NaPF}_{6} / \mathrm{EC}$ - DEC electrolyte at a scan rate of $0.2 \mathrm{mVs}^{-1}$. (b) Ex situ XRD patterns during the $\mathrm{CV}$ cycles.

(c) Transmission electron microscopy (TEM) image of the pristine $\mathrm{Ti}_{2} \mathrm{CT}_{x}$. (d) TEM image of activated $\mathrm{Ti}_{2} \mathrm{CT}_{x}$ after the first $\mathrm{CV}$. 


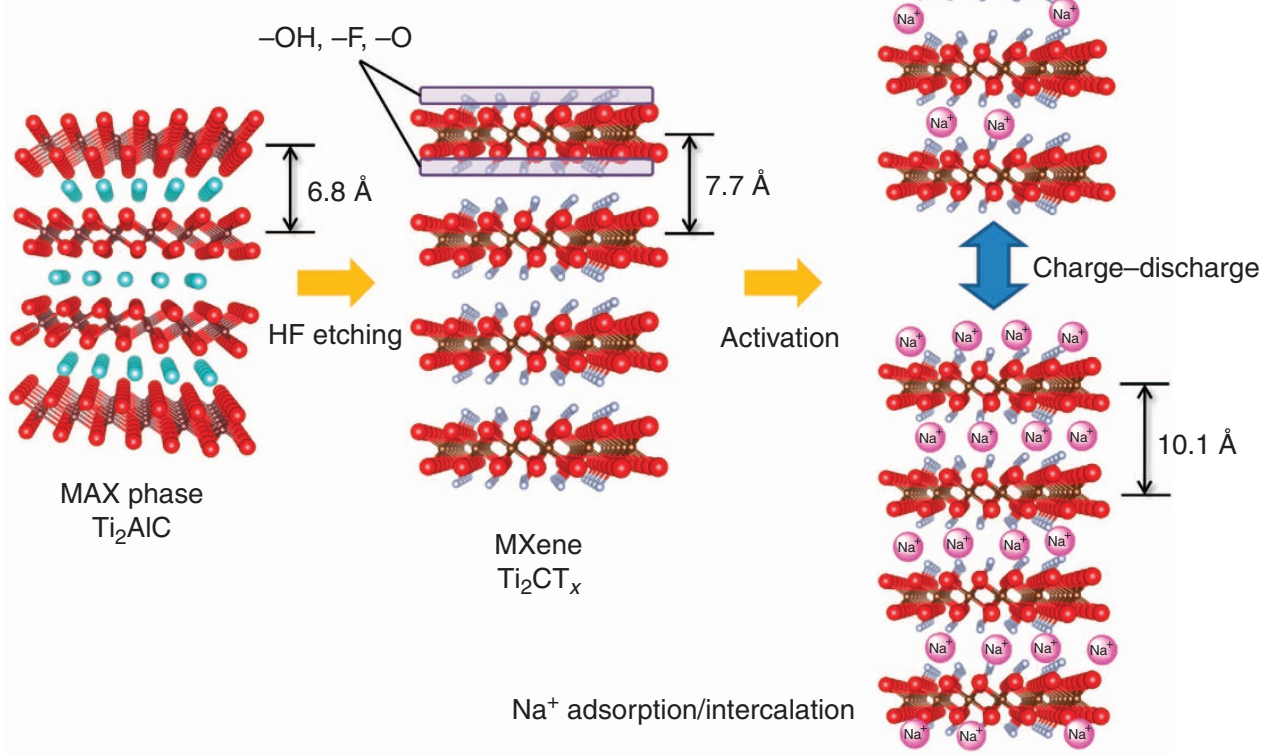

Figure 2 | Schematic illustration of the reaction mechanism of $\mathbf{T i}_{\mathbf{2}} \mathbf{C T}_{\mathbf{x}}$ by electrochemical activation. The MAX phase $\mathrm{Ti}_{2} \mathrm{AIC}$ is transformed to the MXene $\mathrm{Ti}_{2} \mathrm{CT}_{x}$ nanosheets by the hydrofluoric acid treatment. $\mathrm{Ti}_{2} \mathrm{CT}_{x}$ exhibits expansion of the interlayer distance by the first $\mathrm{Na}{ }^{+}$intercalation, then reversible $\mathrm{Na}^{+}$(de)intercalation occurs without significant interlayer distance change.

corresponding to typical capacitor behaviour. In addition, a reversible pair of relatively sharp cathodic/anodic peaks is observed at $\sim 2.3 \mathrm{~V}$ in each cycle. Although the (002) diffraction peak does not shift during the cycles, EDX confirms a reversible change in the $\mathrm{Na}$ content, and X-ray photoelectron spectroscopy (XPS) detects a reversible spectral change in the Ti $2 p$ XPS spectrum (Supplementary Fig. 3), which is indicative of a charge transfer reaction. Therefore, the current flow from $\mathrm{Ti}_{2} \mathrm{CT}_{x}$ in the nonaqueous $\mathrm{Na}^{+}$electrolyte is attributable to the pseudocapacitance without exhibiting shrinkage/expansion of the interlayer distance.

As reported previously, $\mathrm{Ti}_{3} \mathrm{C}_{2} \mathrm{~T}_{x}$ and $\mathrm{Ti}_{2} \mathrm{CT}_{x}$ in a nonaqueous $\mathrm{Li}^{+}$electrolyte exhibit shrinkage/expansion of the interlayer distance during the cycle 27,28 . For example, $\mathrm{Ti}_{2} \mathrm{CT}_{x}$ in a nonaqueous $\mathrm{Li}^{+}$electrolyte exhibits a change in the interlayer distance between 18.7 and $18.0 \AA$ ( $4 \%$ change). In contrast, bare $\mathrm{Na}^{+}$is intercalated between the MXene sheets for $\mathrm{Ti}_{2} \mathrm{CT}_{x}$ in a nonaqueous $\mathrm{Na}^{+}$electrolyte to expand the interlayer distance from 7.7 to $10.1 \AA$ during the first cathodic process (Fig. 2, activation). Then, activated $\mathrm{Ti}_{2} \mathrm{CT}_{x}$ allows reversible $\mathrm{Na}^{+}$intercalation/ deintercalation into the interlayer space as well as reversible $\mathrm{Na}^{+}$ adsorption/desorption onto the surface of each layer/sheet, where the change in the interlayer distance is small within $\sim 0.1 \AA$ (Fig. 2 and Supplementary Table 2). Because EDX detects residual $\mathrm{Na}^{+}$, even at $3.0 \mathrm{~V}$ (Supplementary Table 1), residual $\mathrm{Na}^{+}$may behave as a pillar between the MXene $\mathrm{Ti}_{2} \mathrm{C}$ layers during the entire charge/ discharge process, maintaining the interlayer distance at an almost constant value. Another possible explanation for the constant interlayer distance is that the expansion due to $\mathrm{Na}^{+}$intercalation is balanced by the Coulombic attraction between the MXene sheets and intercalated $\mathrm{Na}^{33}$.

The CV curves of activated $\mathrm{Ti}_{2} \mathrm{CT}_{x}$ measured at various scan rates (Supplementary Fig. 4) provide insights into the reaction kinetics. The $b$-value analysis $\left(i=a v^{b} ; i\right.$ : current; $v$ : scan rate; $a, b$ : constants) for the peak current at $\sim 2.3 \mathrm{~V}$ gives a $b$-value of unity for $0.05<v<0.5 \mathrm{mV} \mathrm{s}^{-1}$, which is indicative of a surfacecontrolled reaction. Presumably, (de)solvation or charge transfer at the interface rather than slow $\mathrm{Na}^{+}$diffusion in the bulk determines the reaction rate.

$\mathbf{T i}_{2} \mathbf{C T}_{\boldsymbol{x}}$ as negative-electrode material. Having confirmed that activated $\mathrm{Ti}_{2} \mathrm{CT}_{x}$ is a promising candidate as a negative-electrode material for $\mathrm{Na}$-ion hybrid capacitors, galvanostatic charge/discharge experiments were conducted. Here, charging is a cathodic process $\left(\mathrm{Na}^{+}\right.$adsorption/intercalation), whereas discharging is an anodic process $\left(\mathrm{Na}^{+}\right.$desorption/deintercalation). Figure $3 \mathrm{a}$ shows the charge - discharge curves measured between the cutoff voltages of $0.1-3.0 \mathrm{~V}$ versus $\mathrm{Na} / \mathrm{Na}^{+}$at $20 \mathrm{~mA} \mathrm{~g}^{-1}$. The first charge exhibits a voltage plateau at $\sim 0.6 \mathrm{~V}$, delivering a relatively large capacity of $360 \mathrm{mAhg}^{-1}$. The following first discharge curve has a capacitor-type slope in the range of $0.2-2.5 \mathrm{~V}$ but with a much smaller capacity, resulting in a relatively low Coulombic efficiency of $65 \%$ for the first cycle. However, after the initial few cycles for activation, $\mathrm{Ti}_{2} \mathrm{CT}_{x}$ exhibits stable and efficient electrode performance. The charge/discharge profiles exhibit a capacitor-type slope in the range of $0.1-2.3 \mathrm{~V}$ (an average operating potential of $1.3 \mathrm{~V}$ ), delivering a reversible capacity of $\sim 175 \mathrm{mAh} \mathrm{g}^{-1}$ with good cycle stability (Fig. 3b, 12 and $19 \%$ losses of the second capacity after 50 and 100 cycles, respectively). The average operating potential of $1.3 \mathrm{~V}$ is relatively high when used as the negative electrode but is beneficial for stable operation, retaining the capacity at a high rate and avoiding $\mathrm{Na}$ metal plating for safety.

$\mathrm{The} \mathrm{Na} / \mathrm{Ti}$ elemental ratio determined by EDX during the first two cycles allow us to estimate the capacity (Supplementary Fig. 5) for various possible nominal chemical formulae of $\mathrm{Ti}_{2} \mathrm{CT}_{x}$ $\left(\mathrm{Ti}_{2} \mathrm{CO}_{2}, \mathrm{Ti}_{2} \mathrm{C}(\mathrm{OH})_{2}\right.$ and $\left.\mathrm{Ti}_{2} \mathrm{CF}_{2}\right)$. The first experimental charge capacity $\left(359 \mathrm{mAhg}^{-1}\right)$ is larger than the estimated ones $\left(308-321 \mathrm{mAhg}^{-1}\right)$, whereas the first discharge capacity 

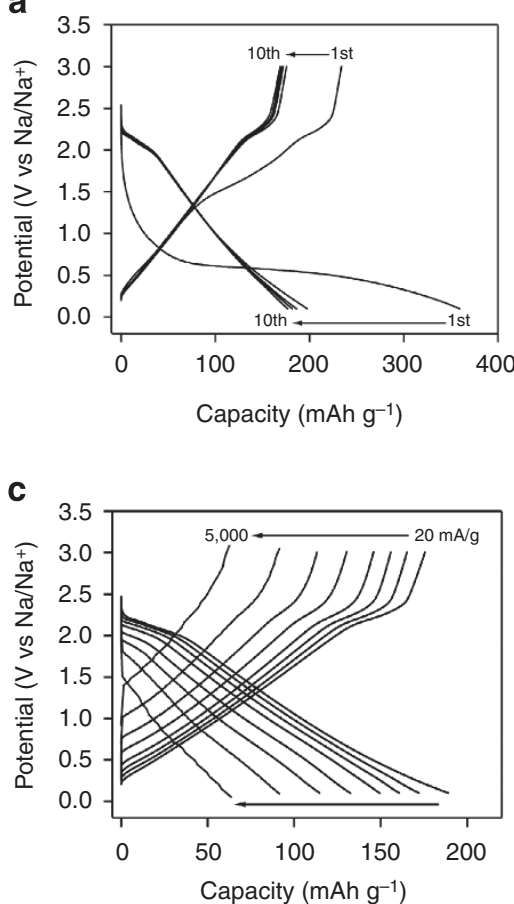

b
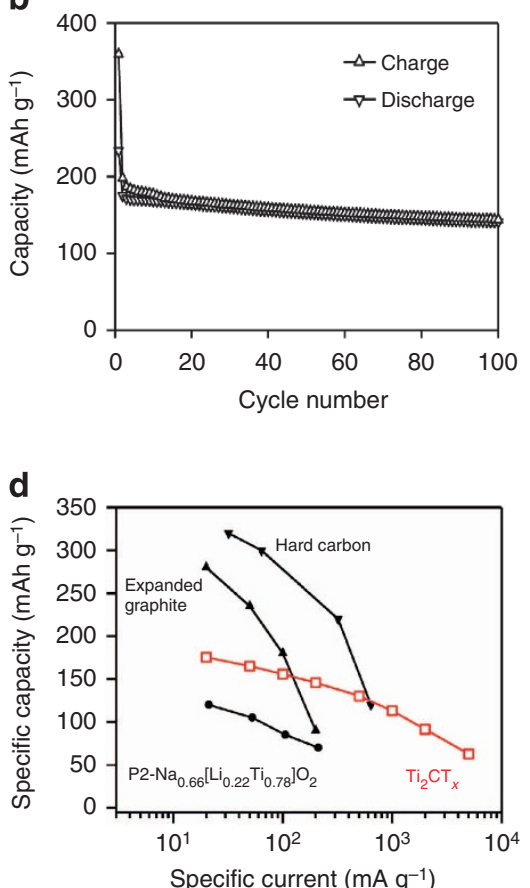

Figure 3 | Electrode performance of $\mathbf{T i}_{\mathbf{2}} \mathbf{C T}_{\mathbf{x}}$ in a $\mathbf{N a}{ }^{+}$nonaqueous electrolyte. (a,b) Charge/discharge curves and cycle stability for $\mathrm{Ti}_{2} \mathrm{CT}_{x}$ in a $1 \mathrm{M}$ $\mathrm{NaPF}_{6} / \mathrm{EC}$ - DEC electrolyte. The specific current is $20 \mathrm{mAg}^{-1}$ with cut-off voltages in the range of $0.1-3.0 \mathrm{~V}$ versus (vs) $\mathrm{Na} / \mathrm{Na}{ }^{+}$. (c) $\mathrm{Charge} /$ discharge curves at various rates. (d) Rate capability for $\mathrm{Ti}_{2} \mathrm{CT}_{x}$, hard carbon ${ }^{11}$, expanded graphite ${ }^{12}$ and $\mathrm{P} 2-\mathrm{Na}_{0.66}\left[\mathrm{Li}_{0.22} \mathrm{Ti}_{0.78}\right] \mathrm{O}_{2}\left(\mathrm{ref}{ }^{19}\right)$.

$\left(233 \mathrm{mAh}^{-1}\right)$ is close to the estimated ones $\left(224-234 \mathrm{mAh}^{-1}\right)$. Thus, the initial irreversible capacity arises from the decomposition of the electrolyte as well as the residual $\mathrm{Na}^{+}$between the MXene layers (vide supra). The electrolyte decomposition during the initial cycles may form stable solid-electrolyte interface, which inhibits continuous electrolyte decomposition.

Figure $3 \mathrm{c}$ shows the charge/discharge profiles of $\mathrm{Ti}_{2} \mathrm{CT}_{x}$ at various specific currents. The reversible capacity is retained, even at extremely high rates $\left(156,113\right.$ and $63 \mathrm{mAh} \mathrm{g}^{-1}$ at $200,1,000$ and $5,000 \mathrm{mAg}^{-1}$, respectively). Figure $3 \mathrm{~d}$ compares the rate capability of $\mathrm{Ti}_{2} \mathrm{CT}_{x}$, hard carbon ${ }^{11}$, expanded graphite ${ }^{12}$ and $\mathrm{P} 2-\mathrm{Na}_{0.66}\left[\mathrm{Li}_{0.22} \mathrm{Ti}_{0.78}\right] \mathrm{O}_{2}$ (ref. 19). Although the carbon compounds (expanded graphite and hard carbon) deliver a high capacity of $\sim 300 \mathrm{mAh} \mathrm{g}^{-1}$ at a low rate, the capacity retention at high rates is much lower than that of $\mathrm{Ti}_{2} \mathrm{CT}_{x}$. $\mathrm{P} 2-\mathrm{Na}_{0.66}\left[\mathrm{Li}_{0.22} \mathrm{Ti}_{0.78}\right] \mathrm{O}_{2}$ is an electrode material without a change in lattice volume during the cycle; therefore, the minimum structural change associated with (de)sodiation enables a high capacity retention at high rates. However, the theoretical capacity of $\mathrm{P} 2-\mathrm{Na}_{0.66}\left[\mathrm{Li}_{0.22} \mathrm{Ti}_{0.78}\right] \mathrm{O}_{2}$ is much smaller than that of $\mathrm{Ti}_{2} \mathrm{CT}_{x} ; \mathrm{Ti}_{2} \mathrm{CT}_{x}$ delivers much higher capacity at any charge/discharge rate. Therefore, $\mathrm{Ti}_{2} \mathrm{CT}_{x}$ is a high-performance electrode material with a high capacity, stability, safety and a high power. It should be emphasized that the high rate capability was obtained with a thick electrode (thickness: $50 \mu \mathrm{m}$ ); therefore, its practical application to Na-ion hybrid capacitors is highly realistic.

Full cell with $\mathrm{Ti}_{2} \mathrm{CT}_{\mathbf{x}}$ and $\mathrm{Na}_{2} \mathrm{Fe}_{2}\left(\mathrm{SO}_{4}\right)_{3}$. To further demonstrate the potential of $\mathrm{Ti}_{2} \mathrm{CT}_{x}$ in $\mathrm{Na}$-ion hybrid capacitors, a prototype full cell (Fig. 4a) was fabricated by utilizing $\mathrm{Ti}_{2} \mathrm{CT}_{x}$ as a negative electrode and alluaudite $\mathrm{Na}_{2} \mathrm{Fe}_{2}\left(\mathrm{SO}_{4}\right)_{3}$ as a positive electrode. Recently, our group has discovered alluaudite $\mathrm{Na}_{2} \mathrm{Fe}_{2}\left(\mathrm{SO}_{4}\right)_{3}$ as a promising positive-electrode material that exhibits a specific capacity of $100 \mathrm{mAhg}^{-1}$ at a high operating potential of $3.8 \mathrm{~V}$ versus $\mathrm{Na} / \mathrm{Na}^{+}$, the highest value among all Fe-based compounds, which enables the Na-ion full cell to achieve both high energy and high power densities ${ }^{34,35}$. The mass balance between the positive and negative electrodes was fixed to $4: 1$ to ensure full activation of $\mathrm{Ti}_{2} \mathrm{CT}_{x}$ during the first charge.

Figure $4 \mathrm{~b}$ shows the charge/discharge curves for the full cell measured at current densities of 150 and $600 \mathrm{mAg}^{-1}$ (based on the weight of $\mathrm{Ti}_{2} \mathrm{CT}_{x}$ ). Note that the first cycle was conducted at $20 \mathrm{mAg}^{-1}$ (based on the weight of $\mathrm{Ti}_{2} \mathrm{CT}_{x}$ ) to activate $\mathrm{Ti}_{2} \mathrm{CT}_{x}$. After the first cycle, the cell exhibits a voltage profile that mainly reflects the potential of $\mathrm{Ti}_{2} \mathrm{CT}_{x}$ because the cell capacity is limited by the $\mathrm{Ti}_{2} \mathrm{CT}_{x}$ negative electrode (Fig. 3a). The average operating voltage is $2.4 \mathrm{~V}$, and the reversible capacities of the second cycle are 133 and $107 \mathrm{mAh} \mathrm{g}^{-1}$ at 150 and $600 \mathrm{~mA} \mathrm{~g}^{-1}$ (based on the weight of $\mathrm{Ti}_{2} \mathrm{CT}_{x}$ ), respectively, achieving theoretical energy densities of 320 and $260 \mathrm{Wh} \mathrm{kg}^{-1}$ at specific power densities of 360 and $1,440 \mathrm{~W} \mathrm{~kg}^{-1}$ (based on the weight of $\mathrm{Ti}_{2} \mathrm{CT}_{x}$ ), respectively.

Both the cycle stability and efficiency of the full cell are extremely high. As demonstrated in Fig. 4c, the loss of the discharge capacity after 100 cycles at $600 \mathrm{mAg}^{-1}$ is only $4 \%$ of the second discharge capacity. Furthermore, the Coulombic efficiency for cycling at $600 \mathrm{mAg}^{-1}$ reaches $\sim 99.7 \%$ after a few initial cycles. The excellent cycle stability and efficiency may be attributed to the pseudocapacitive charge storage mechanism without a large structural change.

Figure $4 \mathrm{~d}$ plots the charge/discharge profiles of the alluaudite $\mathrm{Na}_{2} \mathrm{Fe}_{2}\left(\mathrm{SO}_{4}\right)_{3}-\mathrm{Ti}_{2} \mathrm{CT}_{x}$ full cell at various current rates, demonstrating the promising high-power performance of the cell (Supplementary Fig. 6). The full cell provides reversible capacities of 90 and $40 \mathrm{mAh} \mathrm{g}^{-1}$, even at extremely high rates of 1,000 and $5,000 \mathrm{~mA} \mathrm{~g}^{-1}$ (based on the weight of $\mathrm{Ti}_{2} \mathrm{CT}_{x}$ ). Thus, by utilizing the pseudocapacitive negative electrode, the Na-ion hybrid capacitor overcomes the trade-off limit and potentially surpasses state-of-the-art high-power rechargeable batteries. Although the 
a
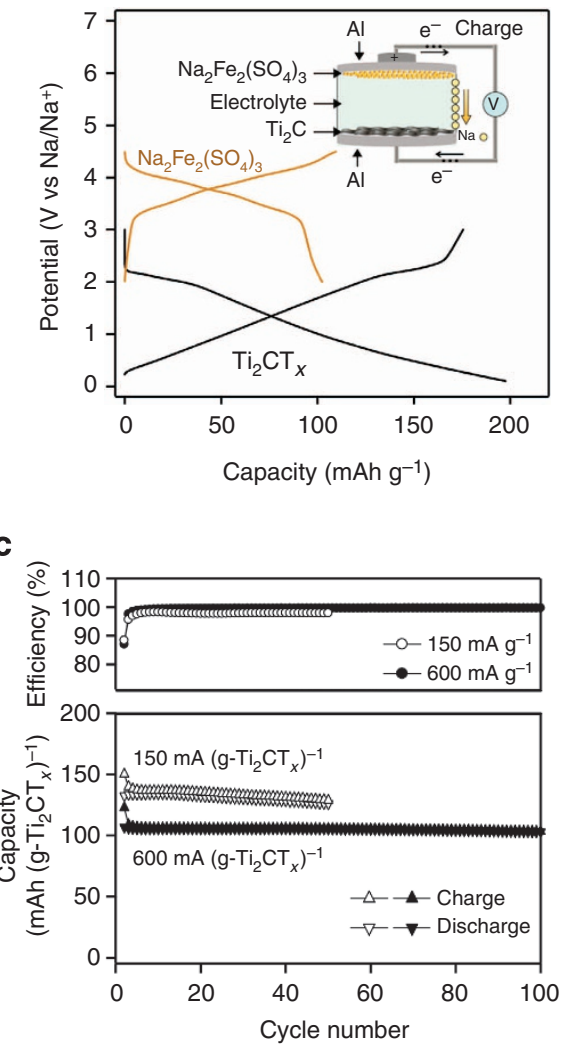

b

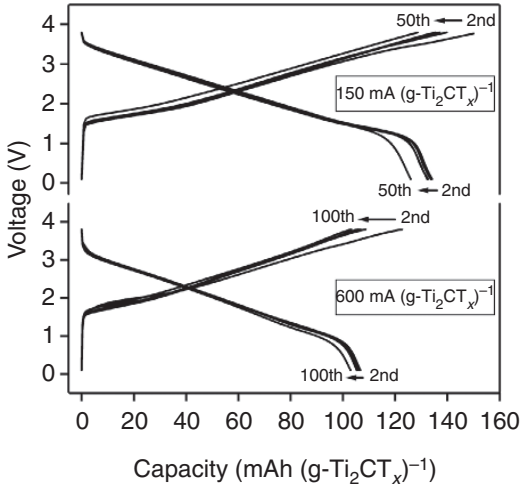

d

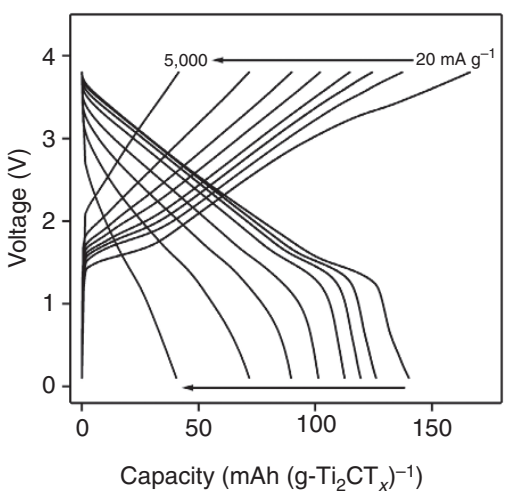

Figure 4 | Performance of the prototype Na-ion hybrid capacitor full cells. (a) Charge/discharge curves of $\mathrm{Ti}_{2} \mathrm{CT}_{x}$ and alluaudite $\mathrm{Na}_{2} \mathrm{Fe}_{2}\left(\mathrm{SO}_{4}\right)_{3}$ versus $\mathrm{Na} / \mathrm{Na}^{+}$; the specific currents are 30 and $6 \mathrm{mAg}^{-1}$, respectively. The inset is a schematic illustration of the $\mathrm{Ti}_{2} \mathrm{CT}_{x}-$ alluaudite $\mathrm{Na}_{2} \mathrm{Fe}_{2}\left(\mathrm{SO}_{4}\right)_{3}$ full cell. (b) Voltage profile of the $\mathrm{Ti}_{2} \mathrm{CT}_{x}$ - alluaudite $\mathrm{Na}_{2} \mathrm{Fe}_{2}\left(\mathrm{SO}_{4}\right)_{3}$ full cell at the specific currents of 150 and $600 \mathrm{~mA}\left(\mathrm{~g}-\mathrm{Ti}_{2} \mathrm{CT} \mathrm{T}_{x}\right)^{-1}$. The specific capacity is normalized by the weight of $\mathrm{Ti}_{2} \mathrm{CT}_{x}$. (c) Cycle stability and Coulombic efficiency of the full cell with cutoff voltages in the range of $0.1-3.8 \mathrm{~V}$ at rates of 150 and $600 \mathrm{~mA}\left(\mathrm{~g}-\mathrm{Ti}_{2} \mathrm{CT}_{x}\right)^{-1}$. (d) Charge/discharge profiles at various rates.

capacity for the total weight of the positive and negative electrode materials in the present prototype cell is limited $\left(26.6 \mathrm{mAh} \mathrm{g}^{-1}\right.$ at a low rate) owing to the excess amount of positive-electrode material, an improvement in the initial Coulombic efficiency could reduce the amount of positive-electrode material, and hence, greatly increase the capacity of the full cell.

\section{Discussion}

Finally, we note a positive perspective for further improvement in the $\mathrm{Ti}_{2} \mathrm{CT}_{x}$ electrode. The gravimetric capacitance from $\mathrm{CV}$ of the $\mathrm{Ti}_{2} \mathrm{CT}_{x}$ electrode in this work is higher than that of previously reported $\mathrm{Ti}_{3} \mathrm{C}_{2} \mathrm{~T}_{x}$ electrodes because of the light weight of $\mathrm{Ti}_{2} \mathrm{CT}_{x}$ (Supplementary Fig. 7). However, very recently, Ghidui et al. ${ }^{36}$ have reported a new method to synthesize $\mathrm{Ti}_{3} \mathrm{C}_{2} \mathrm{~T}_{x}\left(\mathrm{Ti}_{3} \mathrm{C}_{2} \mathrm{~T}_{x}\right.$ 'clay') using a solution of lithium fluoride and hydrochloric acid. The resulting $\mathrm{Ti}_{3} \mathrm{C}_{2} \mathrm{~T}_{x}$ 'clay' delivers a high volumetric capacitance of $900 \mathrm{Fcm}^{-3}$ and a gravimetric capacitance of $245 \mathrm{Fg}^{-1}$, which is much higher than those of the previously reported $\mathrm{Ti}_{3} \mathrm{C}_{2} \mathrm{~T}_{x}$ electrodes and the $\mathrm{Ti}_{2} \mathrm{CT}_{x}$ electrode in this work. According to Ghidui et al. ${ }^{36}$, the $\mathrm{Ti}_{3} \mathrm{C}_{2} \mathrm{~T}_{x}$ clay provides a much higher capacitance at higher rates owing to the improved accessibility of the interlayer spacing. Therefore, the synthetic procedure applied for the $\mathrm{Ti}_{3} \mathrm{C}_{2} \mathrm{~T}_{x}$ clay, that is, the $\mathrm{LiF}+\mathrm{HCl}$ treatment, could further improve the performance of $\mathrm{Ti}_{2} \mathrm{CT}_{x}$.

In summary, the use of the pseudocapacitance of MXene nanosheets was demonstrated as an effective strategy for developing high-performance Na-ion hybrid capacitors. A pseudocapacitance with no significant structural changes can store more charge at a faster charge-discharge rate relative to the ion intercalation and double-layer mechanisms. In the present case, $\mathrm{Ti}_{2} \mathrm{CT}_{x}$ operates as a pseudocapacitor electrode material at $1.3 \mathrm{~V}$ on average versus $\mathrm{Na} / \mathrm{Na}^{+}$with a reversible capacity of $175 \mathrm{mAhg}^{-1}$. The alluaudite $\mathrm{Na}_{2} \mathrm{Fe}_{2}\left(\mathrm{SO}_{4}\right)_{3}-\mathrm{Ti}_{2} \mathrm{CT}_{x}$ prototype cell delivers a high specific energy of $260 \mathrm{Wh} \mathrm{kg}^{-1}$ at a high specific power of $1.4 \mathrm{~kW} \mathrm{~kg}^{-1}$ (based on the weight of $\mathrm{Ti}_{2} \mathrm{CT}_{x}$ ), which overcomes the trade-off limit associated with conventional electrochemical energy storage. By exploiting the compositional and structural versatility of MAX phases and the resulting optimized MXenes, we could further extend the possible sets of electrodes for advanced $\mathrm{Na}$-ion hybrid capacitors.

\section{Methods}

Synthesis of $\mathbf{T i}_{\mathbf{2}} \mathbf{C} \mathbf{T}_{\boldsymbol{x}}$. $\mathrm{Ti}_{2} \mathrm{AlC}$ was prepared by heating a precursor mixture of $\mathrm{TiC}$ (>99\%, High Purity Chemicals, Japan), Ti (>99\%, High Purity Chemicals, Japan) and $\mathrm{Al}$ ( $>99.9 \%$, High Purity Chemicals, Japan) at $1,300{ }^{\circ} \mathrm{C}$ for $1 \mathrm{~h}$ in an Ar gas environment. $\mathrm{Ti}_{2} \mathrm{CT}_{x}$ was synthesized by treating $1 \mathrm{~g}$ of $\mathrm{Ti}_{2} \mathrm{AlC}$ powder in $10 \% \mathrm{HF}$ aqueous solution (Wako) for $12 \mathrm{~h}$ at room temperature. The HF-treated powder was dried in vacuum at $60^{\circ} \mathrm{C}$ for $24 \mathrm{~h}$.

Materials characterization. Powder X-ray diffraction patterns were recorded on a Rigaku RINT-TTR III powder diffractometer with $\mathrm{Cu} \mathrm{K} \alpha$ radiation in a step of $0.02^{\circ}$ over a $2 \theta$ range of $10-80^{\circ}$. Scanning electron microscopy measurements were carried out on a JEOL 6510FA apparatus equipped with an energy dispersive $\mathrm{X}$-ray (EDX) spectrometer for chemical analysis. Transmission electron microscopy was conducted on a JEOL JEM-2100 at $200 \mathrm{kV}$. X-ray photoelectron spectroscopy (XPS) data were collected using a ULVAC PHI 5000 VersaProbe spectrometer with monochromatized $\mathrm{Al} \mathrm{K} \alpha$ radiation $(h v=1,486.6 \mathrm{eV})$. The pressure in the analysis chamber during the measurements was maintained in the $10^{-7} \mathrm{~Pa}$ range. The powder sample was pressed onto conductive carbon, and peaks were recorded with a constant pass energy mode of $117 \mathrm{eV}$ for survey investigation. High-resolution spectra were taken at a pass energy of $23 \mathrm{eV}$, with a step of $0.1 \mathrm{eV}$. 
All binding energies were referenced to that of free carbon at $284.5 \mathrm{eV}$. The crystal structure was drawn using VESTA ${ }^{37}$.

Electrochemical measurement. For electrochemical studies, the working electrode was fabricated by mixing $80 \mathrm{wt} \% \mathrm{Ti}_{2} \mathrm{CT}_{x}, 10 \mathrm{wt} \%$ acetylene black and $10 \mathrm{wt} \%$ polyvinylidene difluoride binder in a minimal amount of $\mathrm{N}$-methylpyrrolidone (NMP) solvent. This slurry was pasted on an aluminum-foil current collector, and the as-obtained electrode sheet was dried overnight at $120^{\circ} \mathrm{C}$ in vacuum. The electrode thickness and mass loading are $\sim 50 \mu \mathrm{m}$ and $\sim 1 \mathrm{mg} \mathrm{cm}^{-2}$, respectively, for all electrochemical measurements (CV and charge-discharge). CR2032-type coin cells were assembled with $\mathrm{Na}$ metal as the counter electrode, a glass fibre filter (GB$100 \mathrm{R}, \mathrm{ADVANTEC}$ ) as the separator and $1 \mathrm{M} \mathrm{NaPF}_{6}$ in ethylene carbonate-diethyl carbonate $(\mathrm{EC}-\mathrm{DEC}, 1: 1 \mathrm{v} / \mathrm{v} \%)$ as the electrolyte. These cells were assembled inside an Ar-filled glove box (Miwa Inc., Japan) (dew point $<-100 \mathrm{~K}$ ). They were galvanostatically (dis)charged in the potential range $0.1-3.0 \mathrm{~V}$. The gravimetric capacitance in farads per gram from $C V$ is given by $C=\frac{1}{\Delta V} \int^{\frac{s}{s}} \mathrm{~d} V$, where $C$ is the gravimetric capacitance, $j$ is the specific current in amperes per gram, $s$ is the scan rate in volts per second, $V$ is the voltage in volts and $\Delta V$ is the voltage window.

Full cell fabrication. For full cell preparation, alluaudite $\mathrm{Na}_{2} \mathrm{Fe}_{2}\left(\mathrm{SO}_{4}\right)_{3}$ was used as a positive electrode material. Alluaudite $\mathrm{Na}_{2} \mathrm{Fe}_{2}\left(\mathrm{SO}_{4}\right)_{3}$ was synthesized according to the procedure described previously ${ }^{34}$. The full cell was prepared with the alluaudite $\mathrm{Na}_{2} \mathrm{Fe}_{2}\left(\mathrm{SO}_{4}\right)_{3}$ electrode as a positive electrode, the $\mathrm{Ti}_{2} \mathrm{CT}_{x}$ electrode as a negative electrode, a glass fibrr membrane as a separator, and $1 \mathrm{M} \mathrm{NaPF}_{6} / \mathrm{EC}-\mathrm{DEC}$ as an electrolyte. The cut-off voltages were $3.8 \mathrm{~V}$ for charging and $0.1 \mathrm{~V}$ for discharging.

\section{References}

1. Nazri, G. A. \& Pistoia, G. Lithium Batteries (Springer, 2009).

2. Daniel, C. \& Besenhard, J. O. Handbook of Battery Materials (Wiley, 2011).

3. Béguin, F. \& Frạckowiak, E. Supercapacitors (Wiley, 2013).

4. Conway, B. E. Electrochemical Supercapacitors (Kluwer, 1999).

5. Conway, B. E. Transition from "Supercapacitor" to "Battery" behavior in elctrochemical energy storage. J. Electrochem. Soc. 138, 1539-1548 (1991).

6. Augustyn, V. et al. High-rate electrochemical energy storage through $\mathrm{Li}^{+}$ intercalation pseudocapacitance. Nat. Mater. 12, 518-522 (2013).

7. Zhu, Y. et al. Carbon-based supercapacitors produced by activation of graphene. Science 332, 1537-1541 (2011).

8. Mefford, J. T., Hardin, W. G., Dai, S., Johnston, K. P. \& Stevenson, K. J. Anion charge storage through oxygen intercalation in $\mathrm{LaMnO}_{3}$ perovskite pseudocapacitor electrodes. Nat. Mater. 13, 726-732 (2014).

9. Wu, C. et al. Two-dimensional vanadyl phosphate ultrathin nanosheets for high energy density and flexible pseudocapacitors. Nat. Commun. 4, 2431 (2013).

10. Simon, P. \& Gogotsi, Y. Materials for electrochemical capacitors. Nat. Mater. 7, 845-854 (2008)

11. Ponrouch, A., Goñi, A. R. \& Palacín, M. R. High capacity hard carbon anodes for sodium ion batteries in additive free electrolyte. Electrochem. Commun. 27, 85-88 (2013).

12. Wen, Y. et al. Expanded graphite as superior anode for sodium-ion batteries. Nat. Commun. 5, 4033 (2014).

13. Oh, S. M. et al. High electrochemical performances of microsphere $\mathrm{C}-\mathrm{TiO}_{2}$ anode for sodium-ion battery. ACS Appl. Mater. Interfaces 6, 11295-11301 (2014).

14. Senguttuvan, P., Rousse, G., Seznec, V., Tarascon, J. M. \& Palacín, M. R. $\mathrm{Na}_{2} \mathrm{Ti}_{3} \mathrm{O}_{7}$ : lowest voltage ever reported oxide insertion electrode for sodium ion batteries. Chem. Mater. 23, 4109-4111 (2011).

15. Qian, J., Wu, X., Cao, Y., Ai, X. \& Yang, H. High capacity and rate capability of amorphous phosphorus for sodium ion batteries. Angew. Chem. Int. Ed. 52, 4633-4636 (2013).

16. Yu, D. Y. W. et al. High-capacity antimony sulphide nanoparticledecorated graphene composite as anode for sodium-ion batteries. Nat. Commun. 4, 2922 (2013).

17. Li, W. et al. $\mathrm{Sn}_{4+} \mathrm{P}_{3} @$ amorphous Sn-P composites as anodes for sodium-ion batteries with low cost, high capacity, long life, and superior rate capability. Adv. Mater. 26, 4037-4042 (2014).

18. Qu, B. et al. Layered $\mathrm{SnS}_{2}$-reduced graphene oxide composite - a high-capacity, high-rate, and long-cycle life sodium-ion battery anode material. Adv. Mater. 26, 3854-3859 (2014).

19. Wang, Y. et al. A zero-strain layered metal oxide as the negative electrode for long-life sodium-ion batteries. Nat. Commun. 3, 2365 (2013).

20. Naguib, M. et al. Two-dimensional nanocrystals produced by exfoliation of $\mathrm{Ti}_{3} \mathrm{AlC}_{2}$. Adv. Mater. 23, 4248-4253 (2011)
21. Naguib, M. et al. Two-dimensional transition metal carbides. ACS Nano 6, 1322-1331 (2012).

22. Mashtalir, O. et al. Intercalation and delamination of layered carbides and carbonitrides. Nat. Commun. 4, 1716 (2013).

23. Lukatskaya, M. R. et al. Cation intercalation and high volumetric capacitance of two-dimensional titanium carbide. Science 341, 1502-1505 (2013).

24. Mashtalir, O., Naguib, M., Dyatkin, B., Gogotsi, Y. \& Barsoum, M. W. Kinetics of aluminum extraction from $\mathrm{Ti}_{3} \mathrm{AlC}_{2}$ in hydrofluoric acid. Mater. Chem. Phys. 139, 147-152 (2013).

25. Halim, J. et al. Transparent conductive two-dimensional titanium carbide epitaxial thin films. Chem. Mater. 26, 2374-2381 (2014).

26. Barsoum, M. W. MAX Phases (Wiley, 2013).

27. Naguib, M. et al. MXene: a promising transition metal carbide anode for lithium-ion batteries. Electrochem. Commun. 16, 61-64 (2012).

28. Come, J. et al. A non-aqueous asymmetric cell with a $\mathrm{Ti}_{2} \mathrm{C}$-based twodimensional negative electrode. J. Electrochem. Soc. 159, A1368-A1373 (2012).

29. Naguib, M. et al. New two-dimensional niobium and vanadium carbides as promising materials for Li-ion batteries. J. Am. Chem. Soc. 135, 15966-15969 (2013).

30. Xie, Y. et al. Role of surface structure on Li-ion energy storage capacity of two-dimensional transition-metal carbides. J. Am. Chem. Soc. 136, 6385-6394 (2014).

31. Xie, Y. et al. Prediction and characterization of MXene nanosheet anodes for non-lithium-ion batteries. ACS Nano 8, 9606-9615 (2014).

32. Dall'Agnese, Y. et al. High capacitance of surface-modified 2D titanium carbide in acidic electrolyte. Electrochem. Commun. 48, 118-122 (2014).

33. Levi, M. D. et al. Solving the capacitive paradox of $2 \mathrm{D}$ MXene using electrochemical quartz-crystal admittance and in situ electronic conductance measurements. Adv. Energy Mater. 5, 1400815 (2015).

34. Barpanda, P., Oyama, G., Nishimura, S., Chung, S. C. \& Yamada, A. A 3.8-V earth-abundant sodium battery electrode. Nat. Commun. 5, 4358 (2014).

35. Ming, J., Barpanda, P., Nishimura, S., Okubo, M. \& Yamada, A. An alluaudite $\mathrm{Na}_{2}+2 x \mathrm{Fe}_{2-x}\left(\mathrm{SO}_{4}\right)_{3}(x=0.2)$ derivative phase as insertion host for lithium battery. Electrochem. Commun. 51, 19-22 (2015).

36. Ghidiu, M., Lukatskaya, M. R., Zhao, M. Q., Gogotsi, Y. \& Barsoum, M. W. Conductive two-dimensional titanium carbide 'clay' with high volumetric capacitance. Nature 516, 78-81 (2014).

37. Momma, K. \& Izumi, F. VESTA 3 for three-dimensional visualization of crystal, volumetric and morphology data. J. Appl. Cryst. 44, 1272-1276 (2011).

\section{Acknowledgements}

This work was financially supported by the Ministry of Education, Culture, Sports, Science and Technology (MEXT), Japan under the 'Elemental Strategy Initiative for Catalysts and Batteries' (ESICB). M.O. was financially supported by the Murata Science Foundation.

\section{Author contributions}

M.O. and A.Y. conceived and directed the project. M.O., X.W., S.K., H.I., E.H., S.O. and I.M. synthesized $\mathrm{Ti}_{2} \mathrm{CT}_{x}$. M.O. and X.W. measured and analysed the electrochemical properties. S.K. measured the performance of the full cells. All authors contributed to the writing of the paper.

\section{Additional information}

Supplementary Information accompanies this paper at http://www.nature.com/ naturecommunications

Competing financial interests: The authors declare no competing financial interests

Reprints and permission information is available online at http://npg.nature.com/ reprintsandpermissions/

How to cite this article: Wang, X. et al. Pseudocapacitance of MXene nanosheets for high-power sodium-ion hybrid capacitors. Nat. Commun. 6:6544 doi: $10.1038 /$ ncomms7544 (2015).

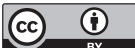

This work is licensed under a Creative Commons Attribution 4.0 International License. The images or other third party material in this article are included in the article's Creative Commons license, unless indicated otherwise in the credit line; if the material is not included under the Creative Commons license, users will need to obtain permission from the license holder to reproduce the material. To view a copy of this license, visit http://creativecommons.org/licenses/by/4.0/ 